\title{
Making and Receiving Offers of Help on Social Media Following Disaster Predict Posttraumatic Growth but not Posttraumatic Stress
}

\author{
Yael Levaot, MA (1); Talya Greene, PhD; Yuval Palgi, PhD
}

ABSTRACT

Objectives: Social media provides an opportunity to engage in social contact and to give and receive help by means of online social networks. Social support following trauma exposure, even in a virtual community, may reduce feelings of helplessness and isolation, and, therefore, reduce posttraumatic stress symptoms (PTS), and increase posttraumatic growth (PTG). The current study aimed to assess whether giving and/or receiving offers of help by means of social media following large community fires predicted PTS and/or PTG.

Methods: A convenience sample of 212 adults living in communities that were affected by large-scale community fires in Israel (November 2016) completed questionnaires on giving and receiving offers of help by means of social media within 1 mo of the fire (W1), and the PTSD checklist for DSM-5 (PCL-5) and PTG questionnaire (PTGI-SF), 4 mo after the fire (W2).

Results: Regression analyses showed that, after controlling for age, gender, and distance from fire, offering help by means of social media predicted higher PTG $(\beta=0.22 ; t=3.18 ; P<0.01)$, as did receiving offers of help by means of social media $(\beta=0.18 ; t=2.64 ; P<0.01)$. There were no significant associations between giving and/or receiving offers of help and PTS.

Conclusions: Connecting people to social media networks may help in promoting posttraumatic growth, although might not impact on posttraumatic symptoms. This is one of the first studies to highlight empirically the advantages of social media in the aftermath of trauma exposure.

Key Words: fire, posttraumatic growth, posttraumatic stress, social media, trauma

S tudies indicate that exposure to a natural or man-made disaster is associated with elevated rates of posttraumatic stress disorder (PTSD), depression, and other anxiety disorders. ${ }^{1}$ In line with this, it has been shown that mental health may be adversely affected following exposure to fires in Australia, ${ }^{2,3}$ California, ${ }^{4}$ and Israel. ${ }^{5}$ On the other hand, research has indicated that not all outcomes following trauma exposure are necessarily adverse, and that people may also experience positive outcomes. ${ }^{6}$

Posttraumatic growth (PTG) is defined as positive psychological change experienced as a result of the struggle with a difficult life circumstance. ${ }^{6} \mathrm{~A}$ traumatic event may challenge core beliefs, forcing reassessment of belief systems, and, therefore, might enhance PTG. ${ }^{7}$ The relationship between posttraumatic stress symptoms (PTS) and PTG is unclear. ${ }^{8}$ Levine et al. ${ }^{9}$ found curvilinear associations between the two, with the highest levels of PTG among those with moderate levels of PTS, while others found that PTG is prevalent among those who screen positive for PTS and showed positive linear associations between PTS and PTG. ${ }^{10,11}$ In a meta-analysis, Shakespeare-Finch and Lurie-Beck ${ }^{12}$ found a significant linear relationship between PTG and PTS symptoms but also a significantly stronger curvilinear relationship.

A significant body of literature suggests that postevent factors play a critical role in influencing mental health. ${ }^{2,13-17}$ Both PTS and PTG are related to the fact that individuals live in an environment in which traumatic events and other factors interact, with the progressive accumulation of risk and resilience. ${ }^{15,18}$ These factors include subsequent events, resources, community functioning, social support, and others. Together, they can compound or buffer the mental health reactions following trauma.

Exposure to traumatic events can occur through experiencing a trauma firsthand or witnessing a trauma as it occurs to others, or through secondary narrative accounts (APA, 2013), and even through media reports that have been shown to be associated with PTSD. ${ }^{19}$ Yeung et $\mathrm{al} .{ }^{20}$ found that, among people who were not directly exposed to a traumatic event, exposure 
to distressing media images, emotional responses, and disasterrelated perceptions, were predictive of probable PTSD several months later.

Social media is becoming increasingly important in both daily life and following disasters. ${ }^{21}$ This growth in social media use may increase the likelihood of indirect trauma exposure through the sharing and viewing of uncensored pictures, videos, and other content. ${ }^{22,23}$ Along with these risks, social media provide benefits to users. Compared with face-to-face encounters, social media users can choose their own level of engagement, and as a result experience greater control. ${ }^{24}$ Furthermore, online communities might be suitable for receiving social support after traumatic events, regardless of geographical location or time. ${ }^{25}$ Perceived social support is a significant predictor of $\mathrm{PTG}^{26}$ and can be used to enhance mental health. ${ }^{27}$ Social support, even in a virtual community, may provide a way of improving feelings of helplessness and reducing isolation through exchange in an online messages.

Relatively little research has focused on motivations for social support provided through social media. ${ }^{28}$ Lee et al. ${ }^{29}$ found that new media use correlated positively with various dimensions of social support and revealed that positive social interaction, and emotional and informational social support were the strongest determinants of quality of life regardless of whether it came from online or offline sources. Baker and Yang $^{30}$ argued that a widely accepted source of social support today is by means of social media platforms. Therefore, social media might function as a central component in coping with the aftermath of a disaster and provide an opportunity to engage in social contact through giving and receiving help by joining online social networks and discussions. ${ }^{31}$

There are 2 key types of social media use: active and passive. ${ }^{32}$ Active social media use has been described as the production of content and interaction between a user and another friend. ${ }^{33}$ Active social media use might also include posting comments or "likes" to content with which the user has no direct relationship. It can be described as a way of identity expression, both self and social. ${ }^{34}$ Active social media use has been shown to affect users beneficially and reduce loneliness and depression. ${ }^{35}$ Previous research has noted the advantage of online narrating and interaction, which provides the benefit of both anonymity and self-disclosure. ${ }^{36}$

In the context of trauma exposure, the use of video recordings, blogs, and forum postings has been described as a fast and simple way to share authentic narratives and to communicate. ${ }^{37}$ Research to date has been uncertain on determining how media use of any type after traumatic events elevates or regulates anxiety and distress. ${ }^{38}$ In a qualitative analysis of narratives, Salzmann-Erikson and Hicdurmaz ${ }^{37}$ indicate that active social media use provides PTSD sufferers a way to experience the universality of the problem and to receive support from others. Moreover, Yoshida et al. ${ }^{39}$ suggested that viewing media coverage can facilitate deliberate rumination, which can be beneficial for posttraumatic recovery and nurturing PTG, and it may be that this is relevant in the case of social media usage too. However, it is unclear whether social media use following traumatic events is associated with PTG.

The present study examined whether making or receiving offers of help by means of social media following fires predicted PTS and/or PTG in a longitudinal study of adults who were living in an area that was exposed to large community fires in Israel. This study examined the impact of active social media use and specifically investigated whether this use was associated with both PTG and PTS. We hypothesized that both receiving more offers of help and offering help by means of social media would predict lower levels of PTS and higher levels of PTG.

\section{METHODS \\ Participants, Sampling, and Procedure}

In November 2016, several large fires erupted throughout Israel, affecting multiple communities. These fires spread rapidly, damaged many properties, and threatened the lives of citizens. According to estimates, 133 people were injured in the fires, around 1800 homes were damaged, and some 70,000 people were temporarily evacuated from their homes (https://www.ynet.co.il/articles/0,7340,L-4884631,00.html).

Data were collected in 2 waves from a convenience sample of individuals living in communities affected by the fires, who were recruited by means of social networking sites and apps, university mailing lists, street outreach, and snowballing methods also described in Palgi et al. ${ }^{40}$ The first wave took place within $1 \mathrm{mo}$ of the fire (December 13, 2016 to December 31, 2016; W1). The sample included 445 individuals aged $18-95$ years $(M=40.23 S D=14.33)$. Most participants completed an online survey using the Qualtrics platform $(n=350)$. Participants recruited by means of street outreach could choose to complete the online survey or complete it by paper and pencil administration $(n=22)$.

To capture symptoms that were after the immediate phase, but would allow us to identify those who developed PTS symptoms or positive change of PTG before 6 mo when the "delayed presentation" of PTS appear (APA, 2013), the second wave took place 4 mo after the fire (March 23, 2017 to April 18, 2017; W2), 212 of the original participants completed online follow-up questionnaires (58.24\%) and were included as the study sample. The questionnaire included an informed consent checkbox. Both waves of the study were approved by the Ethics Committee of the University of Haifa.

Of the participants, $73.9 \%$ were female $(n=176), 63.6 \%$ were married $(n=135)$, and most of them had higher education $(81.7 \% ; n=173)$. Participants included those whose homes were destroyed or damaged by the fire $(21.7 \% ; n=94)$, and 
people who were themselves physically close to the fire (52.6\% were in 0 - to 500 -meter physical distance to the fire).

\section{Measures}

\section{Social Media Offers of Help}

One item was used to examine social media offers of help; participants were asked "Did you offer help by means of social media?" The response format was a Likert scale that ranged from $0=$ not at all, to $4=$ to a large extent.

\section{Social Media Receiving Help}

Participants were asked whether they had received offers of help by means of social media with 3 questions: (1) "Have you received concrete offers of help from people following the fire through social media?" (2) "Have you received emotional offers of help from people following the fire through social media?" (3) "Have you received informative offers of help from people following the fire through social media?" The response format was a Likert scale that ranged from $0=$ not at all, to $4=$ to a large extent. The total score was the sum of responses across all items.

\section{Social Media Use}

Two items were used to examine participants' social media use during and $1 \mathrm{wk}$ after the fire and its perceptions as helpful/ stressful. One question assessed the frequency of social media use following the fire: (1) "I did not use social media"; (2) "I used social media less than usual"; (3) "I used social media as usual"; (4) "I used social media more than usual".

The second question asked participants to indicate whether social media use was experienced as helpful or stressful. Range from $1=$ "social media use did not help me and stressed me a lot" to $5=$ "social media use helped me a lot".

\section{PTS}

PTS were assessed at W2, 4-5 mo after the fire with a translated and back-translated Hebrew version of the PTSD Checklist for DSM-5 (PCL-5, Weathers et al., 2013). ${ }^{41}$ The questionnaire was translated and back-translated. This questionnaire is a 20 item measure and participants rate each symptom experienced during the previous month on a 5 -point Likert scale from $0=$ not at all to $4=$ extremely. Participants were asked to rate each symptom while thinking of the most stressful event related to the fire that they had reported. PTSD symptom score was the sum of ratings. Internal reliability was excellent (Cronbach's alpha $\alpha=.95$ ).

\section{PTG}

PTG was assessed at W2 by a Hebrew version of the Posttraumatic Growth Inventory-Short Form (PTGI-SF, Cann et al., 2010)..$^{42}$ The questionnaire was translated and back-translated. Participants were asked to rate each item on a scale that ranged from $0=$ "I did not experience this change," to $4=$ "I experienced this change to a great deal." A sum score was computed across all items. Higher scores indicated higher levels of PTG symptoms. Reliability was excellent (Cronbach's alpha $\alpha=.90$ ).

Covariates included the following demographics: age, gender, education and marital status $(1=$ married or living with a partner; $2=$ single; $3=$ single-parent, divorced or widowed). In addition, we asked participants: (1) whether they evacuated their homes on the day of the fire, (2) their nearest personal distance to the fires in meters according to the following categories: $a=0-200 ; b=200-500 ; c=500-1000 ; d=1000$ 2500; $e=2500-5000 ; f=>5000$, (3) the proximity of their home to the fires in meters on the following categories: $\mathrm{a}=0-200 ; \mathrm{b}=200-500 ; \mathrm{c}=500-1000 ; \mathrm{d}=1000-2500 ; \mathrm{e}=$ $2500-5000 ; \mathrm{f}=>5000$.

\section{Data Analysis}

Analysis was conducted using SPSS versus 23 software. Linear regression analyses was performed to investigate whether making and/or receiving offers of help by means of social media predicted subsequent PTS and PTG, above and beyond background variables. Covariates (age, gender, marital status, education, and exposure to the fire) were entered in the first step of the regression.

\section{RESULTS}

The demographic characteristics of 212 participants who completed both waves of data collection are summarized in Table 1. Of the participants, $72.4 \% ;(n=154)$ indicated their use of social media outlets following the fires as "more than usual". Moreover, the majority of participants indicated that social media use was more helpful than stressful on a scale of $0-5(M=3.82 ; S D=1.298)$. Women reported significantly higher PTG $(M=6.28 ; \mathrm{SE}=.592)$ than men $(\mathrm{M}=3.15 ; \mathrm{SE}=.679), t(198)=2.578 ; P<0.01$. There were no significant differences on PTS between women and men $t(198)=1.344, P>0.05$.

To quantify the strength of the relationship between the variables, we calculated Pearson correlation coefficients (see Table 1). Making and receiving offers of help on social media were positively associated with each other, indicating that people who received help were more likely to give help and vice versa. Both receiving and making offers of help on social media were positively associated with PTG, but there was no significant correlation with PTS. A positive association was found between PTG and PTS at W2.

Two separate sets of linear regression analyses were performed to investigate whether (i) making and/or (ii) receiving offers of help by means of social media (W1) predicted subsequent PTS and PTG (W2), above and beyond background variables (see Table 2). Both regressions were controlled for W1 covariates 
TABLE 1

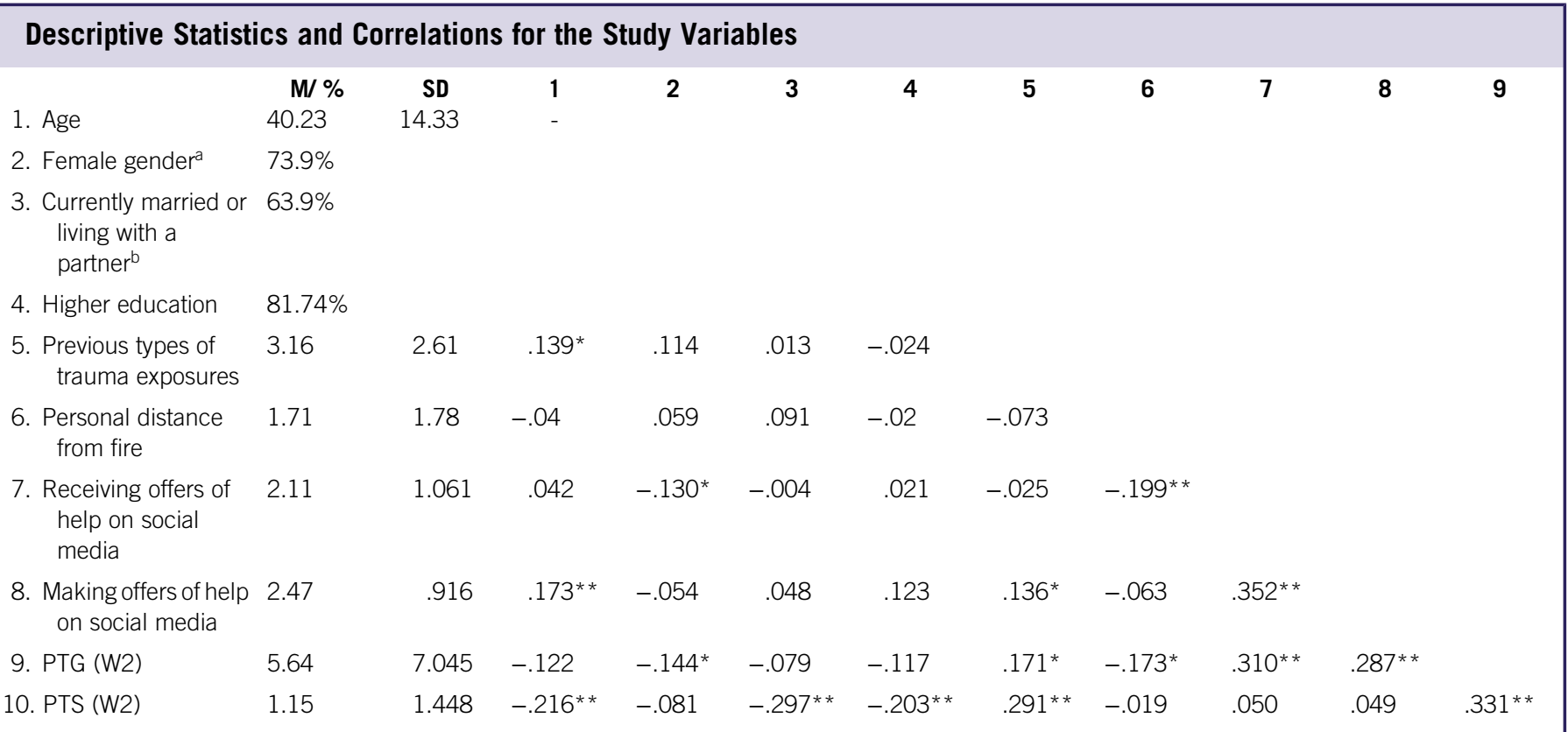

Abbreviations: PTG, posttraumatic growth; PTS, posttraumatic stress symptoms.

** $P<0.01$.

\section{TABLE 2}

\begin{tabular}{|c|c|c|c|c|c|c|c|}
\hline \multicolumn{8}{|c|}{ Linear Regression for Variables Predicting PTG and PTS $(\mathbf{N}=212)$} \\
\hline & & B & SE & $\beta$ & B & SE & $\beta$ \\
\hline & Age & -.037 & .042 & -.075 & -.076 & .075 & -.075 \\
\hline & Gender & -1.88 & 1.206 & -.110 & -3.111 & 2.151 & -.091 \\
\hline & Relationship status & 1.376 & 1.086 & .118 & -6.125 & 1.894 & $-.235^{* *}$ \\
\hline & Distance from fire & -.431 & .268 & -.109 & .83 & .481 & .011 \\
\hline & PTS & 1.66 & .039 & $.331^{* * *}$ & - & - & - \\
\hline & PTG & - & - & - & .526 & .124 & $.263^{* * *}$ \\
\hline$R^{2}$ & \multicolumn{2}{|l|}{.166} & \multicolumn{5}{|c|}{.272} \\
\hline \multirow[t]{8}{*}{ Step 2} & (Constant) & .926 & 3.273 & & 21.077 & 6.011 & \\
\hline & Previous exposure & .120 & .201 & .044 & 2.100 & .349 & $.383^{* * *}$ \\
\hline & Distance from fire & .282 & .259 & .071 & .137 & .493 & .017 \\
\hline & PTS & .150 & .037 & $.300 * * *$ & & & \\
\hline & PTG & & & & .539 & .133 & $.270 * * *$ \\
\hline & $\begin{array}{l}\text { Making offers of help on } \\
\text { social media }\end{array}$ & 1.387 & .459 & $.208^{* * *}$ & -.667 & .889 & -.050 \\
\hline & $\begin{array}{l}\text { Receiving offers of help } \\
\text { on social media }\end{array}$ & .492 & .185 & $.185^{* * *}$ & .154 & .357 & .029 \\
\hline & 263 & & & & .272 & & \\
\hline
\end{tabular}

Abbreviations: PTG, posttraumatic growth; PTS, posttraumatic stress symptoms.

** $P<0.01$.

*** $P<0.001$ 
in Step 1 (age, gender, marital status, education, and exposure to the fire) when predicting W2 outcomes. In addition, for the PTS outcome, we controlled for PTG, while for the PTG outcome we controlled for PTS. We then entered both making and receiving offers help by means of social media at W1, in the second step. Results showed that receiving offers of help on social media predicted higher PTG $(\beta=0.28 ; t=4.13$; $P<0.00)$ as did offering help by means of social media $(\beta=2.71 ; t=3.97 ; P<0.00)$. The final model explained $26.3 \%$ of the variance of PTG. However, no significant association was found between offering help by means of social media and PTS levels at W2, nor receiving offers of help by means of social media and PTS at W2, and the addition of these variables did not explain any additional variance beyond the first step, which explained $27.2 \%$ of the variance in PTS.

\section{DISCUSSION}

To the best of our knowledge, the present study is the first to examine the relationship between offering and/or receiving offers of help by means of social media following exposure to traumatic events with both PTS and PTG. Our results show that, while both offering and receiving more offers of help by means of social media were related to higher subsequent PTG at W2, there was no association with PTS.

Two theories bring to light the potential positive impact of active social media use following trauma exposure. Using the "Uncertainty Reduction" theory ${ }^{43}$ as a lens, researchers who have studied postdisaster media use have argued that information-seeking is a common response among individuals, and serves as a means for individuals to alleviate anxiety induced by the resulting uncertainty of the disaster context. ${ }^{44}$ This tendency is particularly relevant in threatening situations and invites reappraisal of uncertainty feelings by means of active information seeking. ${ }^{45}$ While in the past, individuals turned to traditional media sources for information, social media is increasingly serving this purpose.

An additional theory, the "Uses and Gratifications" theory (UGT) is an approach to understanding why and how people actively seek out specific media to satisfy specific needs. ${ }^{46}$ UGT discusses how users deliberately choose media that will satisfy certain needs and allow individuals to enhance knowledge, relaxation, social interactions, diversion, or escape. ${ }^{47}$ According to these two theories in the context of social media use following traumatic events it is reasonable to assume that people with more PTS are more likely to actively seek out more social media information and interactions relating to the event and at the same time it suggests a possible beneficial outcome of this social media use. However, these theories explain the potential contribution of social media use, but do not explain the need for making and receiving offers of help.
Previous research showed that exposure to emotional responses on social media was, on one hand, associated with psychological distress, ${ }^{48}$ and on the other hand, there is evidence showing that emotional contagion of positive emotions can spread through online social networks. ${ }^{49}$ Additionally, social media might have a positive effect on framing of the traumatic event as has been showed with traditional media. ${ }^{50}$ Our results indicated that making and receiving offers of help on social media may enhance PTG; however, PTG and PTS often coexist, ${ }^{51}$ and we found a lack of association between social media use of both making and receiving help and PTS. This supports a possible explanation found in previous studies showing that PTS and PTG had different predictive paths. ${ }^{52,53}$ Social media use of offering and receiving help predicted PTG but not PTS. This finding might also be explained by previous study that found an association between PTSD and media exposure only when the media source was perceived as stressful. ${ }^{54}$

Our results show that offering help and receiving offers of help are connected to each other and both might be psychologically beneficial. Social media provides an immediate and potentially constant source of social support. The benefits of receiving support from others are well established; however, supporting others is also beneficial and leads to increases in sense of belonging, ${ }^{55}$ increased self-esteem, ${ }^{56}$ self-worth, ${ }^{57}$ social connection, ${ }^{58}$ and sense of control. ${ }^{59}$ These findings add to recent studies that point to a rewardrelated psychological mechanisms of giving support. ${ }^{60}$

Earlier research suggested that PTG is facilitated when positive cognitions are translated into positive action. ${ }^{61,62}$ Offering help through any kind of medium, including on social media, could be described as an action-focused coping mechanism that might explain the association between offering help and PTG. Tandoc and Takahashi ${ }^{63}$ found that social media provided a means for trauma survivors to interact and participate in the social construction of their experience. In addition, Hall et al. ${ }^{23}$ found that participants who reported higher psychological distress actively participated in social media, which may potentially influence their interpretation of the event and improve resiliency.

A literature review on coping with trauma ${ }^{64}$ indicated that the cultural context of the participants should be taken into consideration to understand the cognitive, behavioral, and emotional processes of individuals following exposure to traumatic events. Therefore, it is possible that, in more collectivistic societies such as Israel, the action of offering and asking for help might turn one's individual coping to a collective coping. Furthermore, online social contact is connected to lower feelings of loneliness, ${ }^{65}$ and perhaps most importantly in creating a sense of community. ${ }^{66}$ Our results support the findings of Reifegerste et al ${ }^{67}$ that social support in online communities depends on an individual's activity, 
and that online activity is significantly correlated with perceived informational and emotional support.

The results of this study contribute to a growing body of literature suggesting that support giving is a protective factor and can benefit mental health. However, some limitations require attention. First, self-report questionnaires do not represent objective information on social media use, both in terms of intensity of use, and in terms of content. Second, the participants reported on their social media use between 2 and $4 \mathrm{wk}$ after being exposed to the fire, so their responses may be subject to recall bias. Third, the study is based on a convenience sample which limits generalization of the findings. Future research is needed to examine the long-term interactions of objective active social media use following trauma exposure and both positive and pathological mental health outcomes.

\section{CONCLUSIONS}

This is one of the first studies to highlight empirically the advantages of social media in the aftermath of trauma exposure. The current study has clinical implications, indicating that both receiving and offering help could promote positive adaptation and growth, although might not reduce psychological distress nor mitigate posttraumatic symptoms. Connecting with online social networks that promote a viable source of social support and sense of community, may be helpful for individuals following trauma exposure. Social media use is increasing exponentially; understanding the potential role it could have in recovery from trauma exposure, particularly when whole communities are affected, is crucial, and many more studies are needed in this vein.

\section{About the Authors}

Department of Community Mental Health, University of Haifa, Mount Carmel, Israel (Mrs Levaot, Dr Greene) and Department of Gerontology and the Center for Research and Study of Aging, University of Haifa, Mount Carmel, Israel (Prof Palgi).

Correspondence and reprint requests to Talya Greene, Department of Community Mental Health, University of Haifa, Mount Carmel, Israel (e-mail: tgreene@univ. haifa.ac.il).

\section{Acknowledgments}

The authors whose names are listed above certify that they have NO affiliations with or involvement in any organization or entity with any financial interest, or nonfinancial interest in the subject matter or materials discussed in this manuscript. Data will be made available on request.

\section{REFERENCES}

1. Adeback P, Schulman A, Nilsson D. Children exposed to a natural disaster: psychological consequences eight years after 2004 tsunami. Nord J Psychiatry. 2018;72(1):75-81.

2. Forbes D, Alkemade N, Waters E, et al. The role of anger and ongoing stressors in mental health following a natural disaster. Aust N Z J Psychiatry. 2015;49(8):706-713.
3. McFarlane AC. The longitudinal course of posttraumatic morbidity. The range of outcomes and their predictors. J Nerv Ment Dis. 1988; 176(1):30-39.

4. Felix ED, Afifi W. The role of social support on mental health after multiple wildfire disasters. J Community Psychol. 2015;43(2):156-170.

5. Hashoul-Andary R, Assayag-Nitzan Y, Yuval K, et al. A longitudinal study of emotional distress intolerance and psychopathology following exposure to a potentially traumatic event in a community sample. Cognit Ther Res. 2016;40(1):1-13.

6. Tedeschi RG. Posttraumatic growth in combat veterans. J Clin Psychol Med Settings. 2011;18(2):137-144.

7. Taku K, Cann A, Tedeschi RG, Calhoun LG. Core beliefs shaken by an earthquake correlate with posttraumatic growth. Psychol Trauma. 2015; 7(6):563-569.

8. Greene T, Lahav Y, Kanat-Maymon Y, et al. A longitudinal study of secondary posttraumatic growth in wives of ex-POWs. Psychiatry. 2015;78(2): 186-197.

9. Levine SZ, Laufer A, Hamama-Raz Y, et al. Posttraumatic growth in adolescence: examining its components and relationship with PTSD. J Trauma Stress. 2008;21(5):492-496.

10. Hobfoll SE, Canetti-Nisim D, Johnson RJ, et al. The association of exposure, risk, and resiliency factors with PTSD among Jews and Arabs exposed to repeated acts of terrorism in Israel. J Trauma Stress. 2008;21(1):9-21.

11. Tsai J, El-Gabalawy R, Sledge WH, et al. Post-traumatic growth among veterans in the USA: results from the National Health and Resilience in Veterans Study. Psychol Med. 2015;45(1):165-179.

12. Shakespeare-Finch J, Lurie-Beck J. A meta-analytic clarification of the relationship between posttraumatic growth and symptoms of posttraumatic distress disorder. J Anxiety Disord. 2014;28(2):223-229.

13. Acierno R, Ruggiero KJ, Galea S, et al. Psychological sequelae resulting from the 2004 Florida hurricanes: implications for postdisaster intervention. Am J Public Health. 2007;97(Suppl 1):S103-S108.

14. Adams RE, Boscarino JA. Predictors of PTSD and delayed PTSD after disaster: the impact of exposure and psychosocial resources. J Nerv Ment Dis. 2006;194(7):485-493.

15. McFarlane AC. The long-term costs of traumatic stress: intertwined physical and psychological consequences. World Psychiatry. 2010;9(1):3-10.

16. Kessler RC, Galea S, Gruber MJ, et al. Trends in mental illness and suicidality after Hurricane Katrina. Mol Psychiatry. 2008;13:374-384.

17. Neria Y, Nandi A, Galea S. Post-traumatic stress disorder following disasters: a systematic review. Psychol Med. 2008;38(4):467-480.

18. Leppma M, Mnatsakanova A, Sarkisian K, et al. Stressful life events and posttraumatic growth among police officers: a cross-sectional study. Stress Health. 2018;34(1):175-186.

19. May CL, Wisco BE. Defining trauma: how level of exposure and proximity affect risk for posttraumatic stress disorder. Psychol Trauma. 2016;8(2): 233-240.

20. Yeung NCY, Lau JTF, Yu NX, et al. Media exposure related to the 2008 Sichuan Earthquake predicted probable PTSD among Chinese adolescents in Kunming, China: a longitudinal study. Psychol Trauma. 2018;10(2): 253-262.

21. Haupt B, Kapucu N, Morgan J. The use of social media for campus safety. J Emerg Manag. 2017;15(1):17-28.

22. Goodwin R, Palgi Y, Hamama-Raz Y, et al. In the eye of the storm or the bullseye of the media: social media use during Hurricane Sandy as a predictor of post-traumatic stress. Psychiatry Res. 2013;47(8):1099-1100.

23. Hall BJ, Xiong YX, Yip PSY, et al. The association between disaster exposure and media use on post-traumatic stress disorder following Typhoon Hato in Macao, China. Eur J Psychotraumatol. 2019;10(1):1558709.

24. Naslund JA, Aschbrenner KA, Marsch LA, et al. Feasibility and acceptability of Facebook for health promotion among people with serious mental illness. Digit Health. 2016;2. doi: 10.1177/2055207616654822

25. Zaphiris P, Wilson S, Pfeil U. Older adults' perceptions and experiences of online social support. Interact Comput. 2009;21(3):159-172.

26. Baillie SE, Sellwood W, Wisely JA. Post-traumatic growth in adults following a burn. Burns. 2014;40(6):1089-1096. 
27. Lotfi-Kashani F, Vaziri S, Akbari ME, et al. Predicting post traumatic growth based upon self-efficacy and perceived social support in cancer patients. Iran J Cancer Prev. 2014;7(3):115-123.

28. Oh S, Syn SY. Motivations for sharing information and social support in social media: a comparative analysis of Facebook, Twitter, Delicious, YouTube, and Flickr. J Assoc Inf Sci Technol. 2015;66(10):2045-2060.

29. Lee PSN, So CYK, Leung L. Social media and Umbrella Movement: insurgent public sphere in formation. Chin J Commun. 2015;8(4):356-375.

30. Baker B, Yang I. Social media as social support in pregnancy and the postpartum. Sex Reprod Healthc. 2018;17:31-34.

31. Leist AK. Social media use of older adults: a mini-review. Gerontology. 2013;59(4):378-384

32. Burke M, Marlow C, Lento T. Social network activity and social well-being. In: Proceedings of the SIGCHI Conference on Human Factors in Computing Systems. ACM: Atlanta, Georgia, USA, 2010:1909-1912.

33. Escobar-Viera CG, Shensa A, Bowman ND, et al. Passive and active social media use and depressive symptoms among United States adults. Cyberpsychol Behav Soc Netw. 2018;21(7):437-443.

34. Thorbjørnsen H, Pedersen PE, Nysveen H. "This is who I am": identity expressiveness and the theory of planned behavior. Psychol Mark. 2007; 24(9):763-785.

35. Shaw LH, Gant LM. In defense of the internet: the relationship between Internet communication and depression, loneliness, self-esteem, and perceived social support. Cyberpsychol Behav. 2002;5(2):157-171.

36. Joinson AN. Knowing me, knowing you: reciprocal self-disclosure in Internet-based surveys. Cyberpsychol Behav. 2001;4(5):587-591.

37. Salzmann-Erikson M, Hicdurmaz D. Use of social media among individuals who suffer from post-traumatic stress: a qualitative analysis of narratives. Qual Health Res. 2017;27(2):285-294.

38. Englund L, Forsberg R, Saveman BI. Survivors' experiences of media coverage after traumatic injury events. Int Emerg Nurs. 2014;22(1):25-30.

39. Yoshida H, Kobayashi N, Honda N, et al. Post-traumatic growth of children affected by the Great East Japan Earthquake and their attitudes to memorial services and media coverage. Psychiatry Clin Neurosci. 2016; 70(5):193-201.

40. Palgi Y, Dikar SD, Greene T. Evaluating a community fire as human-made vs. natural disaster moderates the relationship between peritraumatic distress and both PTSD symptoms and posttraumatic growth. Anxiety, Stress and Coping. doi: 10.1080/10615806.2020.1755818.

41. Weathers FW, Litz BT, Keane TM, et al. The PTSD Checklist for DSM-5 (PCL-5). 2013

42. Cann A, Calhoun LG, Tedeschi RG, et al. A short form of the Posttraumatic Growth Inventory. Anxiety Stress Coping. 2010;23(2): 127-137.

43. Berger CR, Calabrese RJ. Some explorations in initial interaction and beyond: toward a developmental theory of interpersonal communication. Hum Commun Res. 1975;1(2):99-112.

44. Lachlan KA, Spence PR, Seeger M. Terrorist attacks and uncertainty reduction: media use after September 11. Behav Sci Terror Polit Aggress. 2009;1(2):101-110.

45. Brashers DE, Goldsmith DJ, Hsieh E. Information seeking and avoiding in health contexts. Hum Commun Res. 2002;28(2):258-271.

46. Severin WJ, Tankard JW. Cognitive Consistency and Mass Communication. In: Communication Theories: Origins, Methods, and Uses in Mass Media. New York: Pearson; 1997:159-177.

47. McQuail D. The future of communication studies: a contribution to the debate. In: Carpentier N, Trivundza IT, Pruulmann-Vengerfeldt P,
Sundin E, Olsson T, Kilborn R, Nieminen H, Cammaerts, eds. Media and communication studies interventions and intersections. Tartu, Estonia: Tartu Universityr Presas; 2010, 27.

48. Goodwin R, Lemola S, Ben-Ezra M. Media use and insomnia after terror attacks in France. Psychiatry Res. 2018;98:47-50.

49. Neubaum G, Rösner L, Rosenthal-von der Pütten AM, et al. Psychosocial functions of social media usage in a disaster situation: a multi-methodological approach. Comput Human Behav. 2014;34:28-38.

50. Norris FH, Stevens SP, Pfefferbaum B, et al. Community resilience as a metaphor, theory, set of capacities, and strategy for disaster readiness. Am J Community Psychol. 2008;41(1-2):127-150.

51. Dekel S, Ein-Dor T, Solomon Z. Posttraumatic growth and posttraumatic distress: a longitudinal study. Psychol Trauma. 2012;4(1):94-101.

52. Greene T. Do acute dissociation reactions predict subsequent posttraumatic stress and growth? A prospective experience sampling method study. J Anxiety Disord. 2018;57:1-6.

53. Zhou X, Wu X, Fu F, et al. Core belief challenge and rumination as predictors of PTSD and PTG among adolescent survivors of the Wenchuan earthquake. Psychol Trauma. 2015;7(4):391-397.

54. Palgi Y, Shrira A, Hoffman Y. Negative and positive perceptions of media sources and PTSD symptoms among older adults exposed to missile attacks. Pers Individ Dif. 2017;119:185-188.

55. Nelson SK, Layous K, Cole SW, et al. Do unto others or treat yourself? The effects of prosocial and self-focused behavior on psychological flourishing. Emotion. 2016;16(6):850-861.

56. Piferi RL, Lawler KA. Social support and ambulatory blood pressure: an examination of both receiving and giving. Int J Psychophysiol. 2006;62(2): 328-336.

57. Gruenewald TL, Liao DH, Seeman TE. Contributing to others, contributing to oneself: perceptions of generativity and health in later life. J Gerontol B Psychol Sci Soc Sci. 2012;67(6):660-665.

58. Inagaki TK, Eisenberger NI. Neural correlates of giving support to a loved one. Psychosom Med. 2012;74(1):3-7.

59. Thoits PA. Mechanisms linking social ties and support to physical and mental health. J Health Soc Behav. 2011;52(2):145-161.

60. Inagaki TK. Neural mechanisms of the link between giving social support and health. Ann N Y Acad Sci. 2018;1428(1):33-50.

61. Johnson RJ, Hobfoll SE, Hall BJ, et al. Posttraumatic growth: action and reaction. Appl Psychol. 2007;56(3):428-436.

62. Hobfoll SE, Hall BJ, Canetti-Nisim D, et al. Refining our understanding of traumatic growth in the face of terrorism: moving from meaning cognitions to doing what is meaningful. Appl Psychol. 2007;56(3):345-366.

63. Tandoc EC, Takahashi B. Log in if you survived: collective coping on social media in the aftermath of Typhoon Haiyan in the Philippines. New Media Soc. 2017;19(11):1778-1793.

64. Braun-Lewensohn O. Coping and social support in children exposed to mass trauma. Curr Psychiatry Rep. 2015;17(6):46.

65. Jones NM, Garfin DR, Holman EA, et al. Media use and exposure to graphic content in the week following the Boston Marathon bombings. Am J Community Psychol. 2016;58(1-2):47-59.

66. Comello ML, Francis DB, Marshall LH, et al. Cancer survivors who play recreational computer games: motivations for playing and associations with beneficial psychological outcomes. Games Health J. 2016;5(4): 286-292.

67. Reifegerste D, Wasgien K, Hagen LM. Online social support for obese adults: exploring the role of forum activity. Int J Med Inform. 2017; 101:1-8. 